\title{
DESENVOLVIMENTO DA COMPETÊNCIA COMUNICATIVA ORAL EM PLE: TELETANDEM EM FOCO
}

\author{
Oral communicative competence development in PFL: \\ focusing on teletandem
}

\author{
Rozana Aparecida Lopes MESSIAS' \\ Michael J. FERREIRA²
}

Resumo | Tendo por base a modalidade Teletandem Institucional Integrado - na qual as interações ocorrem planejadas no currículo de uma disciplina (ARANHA; CAVALARI, 2014) - e buscando responder às questões: (a) em que medida a prática de teletandem institucional integrado influencia o desenvolvimento da competência comunicativa oral e (b) que aspectos da fala do interagente de teletandem evidenciam o desenvolvimento de sua produção oral, por um semestre letivo, assistimos e assessoramos as aulas de Língua EstrangeiraPLE, analisamos documentos e acompanhamos o desenvolvimento das atividades de Teletandem de uma turma de uma universidade norte-americana. $\mathrm{O}$ estudo foi desenvolvido com base na metodologia qualitativa (ANDRÉ, 1984; FLICK, 2004); teorias que sustentam a ideia de competência comunicativa oral (CANALE; SWAIN, 1980) e, como parâmetro de proficiência, os descritores do Quadro Europeu Comum de Referência para Línguas (CONSELHO DA EUROPA, 2001). A partir da triangulação dos dados, em análise preliminar, elaboramos um quadro que demonstra a construção da proficiência oral de dois estudantes praticantes de teletandem, bem como expõe diferentes variáveis que podem impactar o desenvolvimento e a avaliação da proficiência em foco.

Palavras-chave | Teletandem institucional integrado. Ensino de PLE. Competência comunicativa oral. Avaliação.
Abstract | Based on the Integrated Institutional Teletandem modality - in which interactions take place as part of the class curriculum (ARANHA; CAVALARI, 2014), this study seeks to answer the following questions:(a)Towhat extent does Integrated Institutional Teletandem practice influence oral competence development? and (b) How does this oral competence development manifest itself in the Teletandem interactor's speech? For a semester, we attended Portuguese as a Foreign Language (PFL) classes while providing support through analyzing materials and accompanying Teletandem activities at a US university. Using qualitative methodology (ANDRÉ, 1984 and FLICK, 2004), oral communicative competence theories (CANALE; SWAIN, 1980) and, as a proficiency parameter, the descriptors from the Common European Framework of Reference for Languages (COUNCIL OF EUROPE, 2001), we developed a framework that demonstrates the building of oral proficiency in two practitioners of Teletandem as well as identifies other variables that may impact the development and evaluation/ assessment of the proficiency in focus.

Keywords | Integrated Institutional Teletandem. PFL teaching. Oral Competence. Evaluation and Assessment.

1 Lopes Messias. UNESP. E-mail: rozanalm@gmail.com. ORCID ID: https://orcid.org/0000-0001-8885-0525 2 Ferreira. Georgetown University. E-mail: mjf62@georgetown.edu. ORCID ID: https://orcid.org/00000002-8984-4140 
- | Desenvolvimento da competência comunicativa oral em PLE: teletandem em foco

\section{Introdução ${ }^{3}$}

O avanço da tecnologia digital desde o final do século passado, em especial, nas últimas duas décadas, tem impactado sobremaneira os processos de ensino e aprendizagem de línguas estrangeiras. As práticas de Teletandem são um exemplo concreto dessa transformação. Iniciado em 2006, como um projeto temático, institui parcerias entre estudantes universitários brasileiros da UNESP e estudantes de universidades estrangeiras. A prática de teletandem configura-se como um contexto virtual, autônomo e colaborativo de aprendizagem no qual pares de falantes, por meio de aplicativos de mensageria, ensinam suas respectivas línguas ou línguas de proficiência e, também, em via recíproca, aprendem a língua do outro (TELLES, 2009; TELLES; VASSALLO, 2009). Atualmente, apesar da condição de finalizado enquanto projeto temático, o Teletandem tem suas práticas continuamente instituídas como ações de ensino-aprendizagem de línguas, instauradas nos câmpus da UNESP em que há cursos de Letras (Assis, São José do Rio Preto e Araraquara).

Ao longo de doze anos, no âmbito das práticas de teletandem, ocorreram transformações no que diz respeito ao formato das parcerias de interação entre as instituições de ensino envolvidas, brasileiras ou estrangeiras, e a forma como essas são conduzidas. Aranha e Cavalari (2014) apresentam, a esse respeito, uma síntese bastante pontual da trajetória das atividades do Teletandem no Brasil, no contexto da UNESP (Universidade Estadual Paulista). As autoras ressaltam que o Teletandem surge facilitado pela tecnologia, "como uma forma de promover o ensino-aprendizagem de línguas estrangeiras por meio de encontros regulares e virtuais entre pares de falantes de línguas diferentes que vivem em países diferentes" (ARANHA; CAVALARI, 2014, p. 184).

Durante, pois, o tempo em que dialogam via aplicativo de mensageria (Skype ou outro), os interagentes devem dividir o tempo destinado a cada idioma de forma equitativa, para que ambos possam beneficiar-se do processo de ensino/aprendizagem. Dessa forma, nas interações, que costumam durar 1 (uma) hora, são destinados 30 (trinta) minutos para a utilização de cada idioma. Nesse espaço de tempo, os pares se revezam no papel de aprendiz e tutor da língua na qual são proficientes, podendo "negociar suas necessidades e preferências ao ensinar-aprender" (ARANHA; CAVALARI, 2014, p. 184). Diante desse quadro, uma modalidade que pode gerar resultados mais observáveis são as parcerias efetivadas na modalidade institucional integrada, quando "as instituições que promovem as parcerias reconhecem o Teletandem como parte das atividades obrigatórias que os alunos devem cumprir dentro de determinada disciplina de língua estrangeira" (ARANHA; CAVALARI, 2014, p. 185).

3 O presente estudo é parte de uma pesquisa apoiada pela FAPESP (Processo no 2017/02937-0). 
A modalidade institucional integrada de teletandem é mais rara por conta, principalmente, de diferenças de fuso-horário entre o Brasil e os países de origem das universidades estrangeiras parceiras. Esse fato dificulta a inserção das práticas de teletandem de forma a coincidir com os horários das aulas de língua nas duas nações envolvidas. Nesse sentido, constatamos que no câmpus de Assis prevalece a emersão de uma terceira modalidade - o teletandem institucional semi-integrado (MESSIAS; TELLES, mimeo) - na qual o tempo cumprido nas práticas de teletandem pode ser computado em horas de laboratório de línguas (para os cursos de Letras) ou Atividade AcadêmicoCientífico Cultural (para todos os cursos de graduação).

A questão, destarte, de integrar ou não o teletandem ao currículo de alguma disciplina de língua estrangeira torna-se significativa quando consideramos, especificamente, o que e quanto os estudantes envolvidos nas interações aprendem de língua. Essa, por sinal, é uma inquietação de muitos docentes de universidades estrangeiras que desejam justificar, institucionalmente, a inclusão das práticas de teletandem no currículo de suas classes de língua estrangeira.

A partir dessa problemática, propusemos uma investigação no contexto de uma universidade estrangeira, onde acompanhamos, por um semestre letivo, uma classe de português como língua estrangeira, nível avançado, praticante de teletandem na modalidade institucional integrada. O objetivo principal dessa imersão foi avaliar de que forma avançava a competência comunicativa oral do grupo em questão e em que medida as práticas de teletandem influenciavam tal progresso. O curso, de forma geral, encontrava-se dividido em dois encontros semanais, sendo uma aula de conversação e outra de interação via teletandem com um grupo de alunos do câmpus da UNESP/Assis. A maioria das atividades obrigatórias versavam sobre a experiência do teletandem (tracking sheets, blog, anotações). Em termos de atividades avaliativas, setenta por cento (70\%) da menção final do curso estava atrelada diretamente à prática de teletandem4.

Diante dessa realidade, acompanhamos 16 aulas de conversação e 12 sessões de teletandem cumpridas pela turma, durante o referido semestre letivo. O objetivo que nos moveu foi responder às questões: (a) em que medida a prática de teletandem institucional integrado influencia o desenvolvimento da competência comunicativa oral? e (b) que aspectos da fala do interagente de teletandem evidenciam esse desenvolvimento? Para esse fim, utilizamos diversos instrumentos de coleta de dados, entre os quais: aplicação

4 Tracking sheet - formulário de autoavaliação da aprendizagem preenchido pelos estudantes após a interação; Blog - após a interação, os estudantes escreviam um texto relatando como havia sido a interação e o postavam em uma pasta organizada, pela professora, no Google Drive. Além dessas duas atividades, os estudantes também postavam as anotações que faziam no decorrer da interação. Sobre essa questão, um dos autores desenvolveu um estudo paralelo, em uma discussão sobre a inserção das práticas de teletandem no currículo. 
- | Desenvolvimento da competência comunicativa oral em PLE: teletandem em foco

de dois questionários - realizados pelo Google forms, anotações, inserção de tarefas no espaço de uma interação, aplicação de um pré e um pós-teste (antes da primeira e depois da última interação), entrevista com a professora de PLE da turma e com o coordenador da área de língua portuguesa do departamento e análise de documentos (syllabus da turma).

Na presente discussão, observamos o primeiro questionário sobre os hábitos individuais de estudo de língua portuguesa cuja aplicação ocorreu antes do término das 12 interações de teletandem e, também, as gravações e transcrições de um pré e pós-teste de proficiência aplicado por nós e pela professora da sala, por sugestão do coordenador da área. Esses dados foram confrontados com uma entrevista efetuada com a professora da turma e com as respostas a outro questionário, aplicado após o encerramento das interações.

Sendo assim, no presente artigo apresentamos parte de um trabalho desenvolvido com o intuito de compreender em que medida a prática de teletandem contribui para o desenvolvimento da competência comunicativa oral em língua portuguesa dos estudantes acompanhados.

\section{A metodologia do estudo}

Para empreender a investigação sobre aspectos que possam demonstrar o desenvolvimento da competência comunicativa oral em língua portuguesa de estudantes praticantes de teletandem, centramo-nos em pressupostos da pesquisa qualitativa, mais especificamente, um estudo de caso. Os estudos de caso, de acordo com André (1984, p.51),

[...] procuram retratar a realidade de forma completa e profunda. Esse tipo de estudo pretende revelar a multiplicidade de dimensões presentes numa dada situação, focalizando-a como um todo, mas sem deixar de enfatizar os detalhes, as circunstâncias específicas que favorecem uma maior apreensão desse todo.

Tendo em vista a materialidade da competência comunicativa oral dos estudantes, atentamos para as transcrições de testes aplicados antes da primeira e depois da última interação de teletandem (pré e pós-testes). Para circundar os sentidos do fenômeno (progresso ou não da competência comunicativa oral), embatemos o observado nos testes com outros instrumentos de coleta de dados. 
Sendo assim, as anotações das observações efetuadas no decorrer do acompanhamento das aulas e das interações e o que manifestou a professora, em entrevista, sobre o desempenho dos alunos, serviram como contraponto para analisar as informações coletadas em dois questionários via Google forms (um, no início do semestre, com o intuito de traçar o perfil de estudos dos alunos, e outro, no final do semestre, com o objetivo de coletar suas impressões acerca das práticas de teletandem e do impacto sobre seu desenvolvimento comunicativo em língua portuguesa).

Agregados a esses instrumentos, consideramos, também, dados de uma entrevista com o coordenador da área de língua portuguesa na universidade. Esse último como uma forma de compreender a relevância destinada à prática de teletandem no currículo dos cursos de língua portuguesa da instituição.

No presente artigo, em vista de ser ainda um estudo inicial, apresentaremos a triangulação (FLICK, 2004) dos instrumentos arrolados com a transcrição da produção oral (pré e pós) de duas estudantes. Tal seleção esteve pautada na forma como ambas descreveram sua rotina de estudos e perfil de proficiência.

\section{Sobre avaliação em teletandem e competência comunicativa}

Avaliar proficiência em língua estrangeira não é, certamente, tarefa simples, pois muitas variáveis devem ser consideradas. Observar o impacto das práticas de teletandem no desenvolvimento da proficiência de seus praticantes é ainda mais complexo, tendo em vista que os estudantes participam, concomitantemente, de outras práticas que podem impactar no seu desenvolvimento linguístico na língua-alvo. Além disso, a avaliação pode ser observada por diversos vieses, por meio da verificação pontual das interações, pela forma como os parceiros corrigem-se mutuamente, ou mesmo por questões linguísticas particulares. Pode-se, também, avaliar produções escritas decorrentes, aspectos específicos da fala etc. Ademais, a avaliação pode considerar todo o processo, pode ser específica e, inclusive, é possível criar instrumentos para que o próprio estudante se autoavalie.

No que tange à temática da avaliação em contexto de teletandem, alguns estudos sobre aspectos particulares já foram desenvolvidos: Brocco (2009), por exemplo, observa o tratamento dado à gramática nas sessões de interação, em especial, na ocasião em que os interagentes fazem a correção de aspectos gramaticais da fala do parceiro e a forma como três livros didáticos de língua portuguesa para falantes de outras línguas abordam a gramática. Em estudo posterior, Brocco (2014) enfatiza a avaliação de produções textuais 
- | Desenvolvimento da competência comunicativa oral em PLE: teletandem em foco

escritas realizadas por professores em formação inicial em uma parceria de teletandem institucional integrado. Nesse caso, o foco da pesquisa centrou-se nos textos escritos em português produzidos pelos estudantes americanos e corrigidos por seus parceiros brasileiros.

Ainda com relação à temática da avaliação em teletandem, Furtoso (2011) desenvolve um trabalho no qual observa a avaliação como elemento constituinte do processo de ensinar e aprender. Por esse ângulo, a produção oral dos envolvidos nas interações de teletandem é observada no que tange aos procedimentos de insumo entre os interagentes. As características da fala no teletandem são, de acordo com a autora, indicadores da necessidade de criação de novos elementos avaliadores, específicos para os contextos on-line. Em estudo posterior, Furtoso e Ferreira (2018) realizaram, com foco na avaliação formativa, uma investigação acerca da implantação de um sistema de autoavaliação da aprendizagem no contexto da mesma universidade americana na qual desenvolvemos o presente trabalho.

Diante do exposto, no âmbito da avaliação de proficiência oral, tem nos inquietado a necessidade de compreender, mais detidamente, em que medida as práticas de teletandem impactam na desenvoltura para falar a língua estrangeira e como tal compreensão pode orientar a atuação do mediador/professor e, consequentemente, em práticas de formação de docentes de línguas, envolvidos em atividades de teletandem. Em um estudo mais concreto, representado por questionários quantitativos e qualitativos de avaliação dos processos de interação em teletandem, Telles (2015) constatou que alunos praticantes de teletandem alegam ter desenvolvido, principalmente, vocabulário e "fluência". Todavia, estudos empíricos com dados coletados do ponto de vista do pesquisador ainda não foram realizados, em particular aqueles que enfocam o desenvolvimento da proficiência oral dos praticantes de teletandem no contexto das práticas de ensino de línguas no qual encontram-se imersos.

A presente investigação, então, busca essa constatação a partir da compreensão de proficiência oral tendo por base os pressupostos de competência comunicativa propostos por Canale e Swain (1980), que entendem tal competência como sendo os conhecimentos e as habilidades que o indivíduo possui sobre a língua. De acordo com esses autores, o conhecimento diz respeito àquilo que o indivíduo sabe "de forma consciente ou inconsciente sobre a língua e sobre outros aspectos do uso comunicativo da língua" (OLIVEIRA, 2007, p. 68).

Tendo em vista essas breves considerações, para a análise sobre o desenvolvimento da competência comunicativa oral dos estudantes, baseada nos testes de proficiência 
(pré e pós-interações de teletandem), utilizamos como apoio os elementos de avaliação do Quadro Europeu Comum de Referência para Línguas (CONSELHO DA EUROPA, 2001), uma vez que o consideramos como um parâmetro possível para delimitar a competência comunicativa oral dos participantes. A escolha deveu-se à clareza, à objetividade e à organização de seus descritores, os quais permitem descrever o que o aluno é capaz de fazer com a língua estrangeira que está aprendendo, em oposição ao que ele "não é capaz". Esse documento mensura, a partir da observação de níveis que variam do mais básico ao mais avançado (A1, A2, B1, B2, C1, C2), as diversas competências acionadas pelo aprendiz no processo de comunicação em língua estrangeira. Nesse caso, especificamente, enfatizaremos elementos da competência comunicativa (linguísticas, sociolinguísticas e pragmáticas), conforme expresso no Quadro Europeu Comum de Referência para Línguas (CONSELHO DA EUROPA, 2001, p. 156-177). De forma sintética, a partir da proposta desse documento, elaboramos o quadro que segue: 
- Desenvolvimento da competência comunicativa oral em PLE: teletandem em foco

Quadro 1. Síntese das competências comunicativas linguística, sociolinguística e pragmática $(Q E C R)$

\begin{tabular}{|c|c|c|}
\hline $\begin{array}{l}\text { Competências } \\
\text { Linguísticas }\end{array}$ & $\begin{array}{l}\text { Competências } \\
\text { sociolinguísticas }\end{array}$ & $\begin{array}{l}\text { Competências } \\
\text { pragmáticas }\end{array}$ \\
\hline $\begin{array}{l}\text { A competência lexical } \\
\text { Consiste no } \\
\text { conhecimento e na } \\
\text { capacidade de utilizar } \\
\text { o vocabulário de uma } \\
\text { língua, bem como, } \\
\text { compreender elementos } \\
\text { lexicais e gramaticais. } \\
\text { (p. 156) } \\
\text { A competência } \\
\text { gramatical } \\
\text { A competência } \\
\text { gramatical pode ser } \\
\text { definida como o } \\
\text { conhecimento dos } \\
\text { recursos gramaticais da } \\
\text { língua e a capacidade } \\
\text { para os utilizar. (p. 161) } \\
\text { A competência } \\
\text { semântica } \\
\text { Trata da consciência } \\
\text { e do controle que o } \\
\text { aprendente possui } \\
\text { sobre a organização do } \\
\text { significado. (p. 165) } \\
\text { A competência } \\
\text { fonológica } \\
\text { Envolve o conhecimento } \\
\text { e a capacidade de } \\
\text { percepção e de } \\
\text { produção de sons } \\
\text { (p. 166). }\end{array}$ & 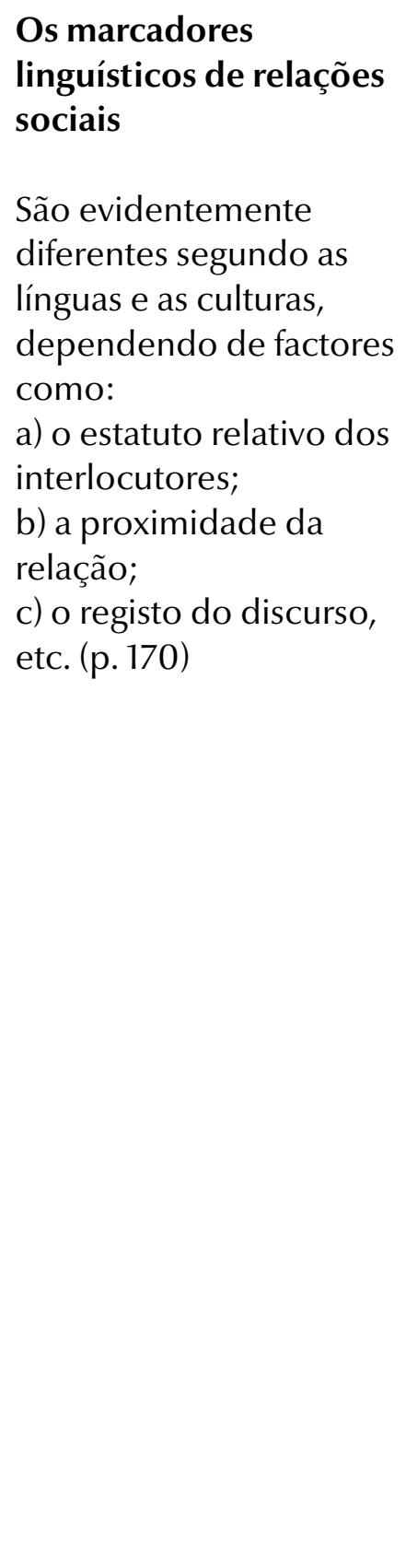 & $\begin{array}{l}\text { As competências } \\
\text { pragmáticas } \\
\text { Dizem respeito ao } \\
\text { conhecimento do } \\
\text { utilizador/ aprendente } \\
\text { dos princípios de } \\
\text { acordo com os quais as } \\
\text { mensagens são: } \\
\text { a) organizadas, } \\
\text { estruturadas } \\
\text { e adaptadas } \\
\text { ("competência } \\
\text { discursiva"); } \\
\text { b) utilizadas para a } \\
\text { realização de funções } \\
\text { comunicativas } \\
\text { ("competência } \\
\text { funcional"); } \\
\text { c) sequenciadas } \\
\text { de acordo com } \\
\text { os esquemas } \\
\text { interaccionais e } \\
\text { transaccionais } \\
\text { ("competência de } \\
\text { concepção"). (p. 174) }\end{array}$ \\
\hline
\end{tabular}




\section{O pré e o pós-teste: mudanças no meio do caminho}

Esclarecemos que, ao princípio da investigação, tencionávamos focalizar a proficiência oral dos estudantes por meio de uma tarefa comunicativa aplicada no ínterim da primeira e da última interação. Todavia, ao iniciarmos as atividades em campo, atentamo-nos para o fato de que testes pré (antes do início das interações) e pós (após o término das 12 interações do semestre) prática de teletandem vinham sendo aplicados para as turmas e concluímos que esse instrumento seria oportuno para a demanda por nós pretendida. Ademais, a tarefa interativa planejada para a primeira e a última interação mostrou-se ineficiente para esse fim, uma vez que não possuíamos a logística necessária para inseri-la nas interações 5 .

Em face do exposto e com o intuito de esclarecer nossa opção por tais testes, ressaltamos que a princípio nos inquietou o fato de aplicar um teste fora da interação de teletandem para observar o desenvolvimento da proficiência comunicativa oral dos estudantes ocasionada por sua participação nessa prática. Inicialmente, pareceu-nos um pouco fora de contexto. Contudo, depois da aplicação da tarefa, do acompanhamento das sessões de teletandem e das aulas, conseguimos traçar um perfil dos estudantes e isso nos possibilitou ter mais instrumentos que "comprovassem" o resultado que o pré e o pós-teste apontaram, mesmo não tendo sido efetuados no ínterim de uma interação de teletandem. Agregada a essas ferramentas, a avaliação acerca do desempenho dos estudantes manifestada pela professora da turma, em entrevista, também contribuiu para delinear o perfil estudantil dos aprendizes, no que tangia a sua relação com a aprendizagem de língua portuguesa.

Quanto à forma de aplicação, o pré-teste foi executado na primeira aula da turma, quando dividimos o grupo e, fora da sala de aula, gravamos o áudio da atividade que consistia em visualizar uma imagem por dois minutos e descrever o que estava acontecendo na situação apresentada. O teste constava em uma folha impressa que, após a facção da atividade, mantínhamos conosco. Todos os estudantes da turma, ao todo 14, fizeram o teste. Dessa totalidade, um foi descartado como possibilidade de análise, pois a estudante não respondeu aos dois questionários enviados, um no início e outro

5 Sobre essa questão desenvolveremos uma discussão mais aprofundada em outro artigo a respeito da metodologia de ensino e formação de professores de línguas. Não conseguimos aplicar a tarefa que planejamos na primeira interação pela inexistência de logística necessária, sobre a qual não havíamos pensado: o mediador do lado brasileiro teria que preparar os alunos para aplicar o teste durante a interação. Todavia, a primeira interação é sempre bastante tumultuada, as pessoas não se conhecem e muitos nunca fizeram teletandem, o que torna a inserção de uma atividade uma ação bastante confusa. Aplicamos a tarefa na terceira interação, apenas, e o resultado serviu muito mais para pensar em questões de metodologia de ensino de línguas do que, necessariamente, para mensurar proficiência comunicativa oral dos alunos. 
- | Desenvolvimento da competência comunicativa oral em PLE: teletandem em foco

no final do semestre. A mesma atividade foi utilizada no pós-teste e o mesmo protocolo foi seguido. Durante a facção da atividade, procurávamos (a) manter um clima distenso, (b) dar dois minutos para o estudante observar a figura e formular sua fala e (c) iniciar a gravação quando o estudante dissesse que estava pronto. Abaixo ilustramos o material utilizado para o pré e pós-teste.

\section{Appendix. Sample Task Prompts for Oral Production test (Pretest, mid-semester, and end-of-semester post-test)}

\section{Sample Picture Description Task}

【Instruction】 Take a look at the picture and describe what the story is about. You have two minutes to prepare. Start narrating the picture when I tell you to do so.

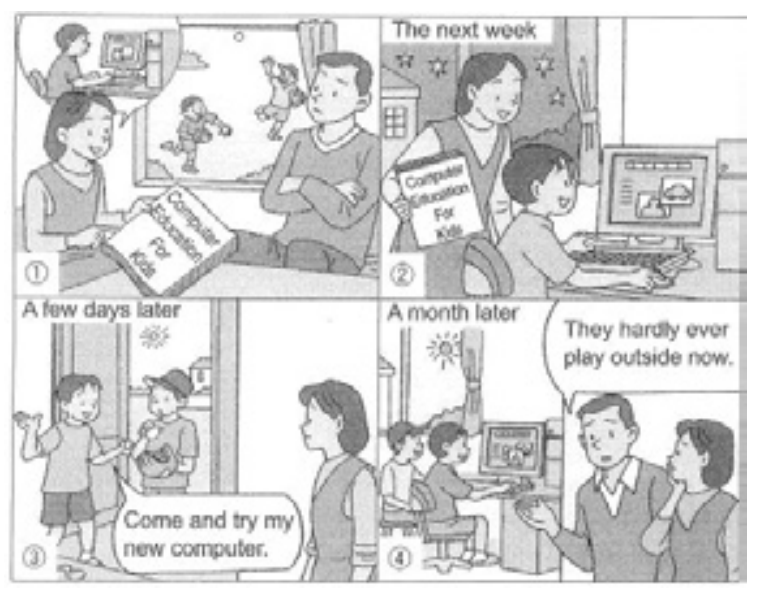

Figura 1. Texto para teste de proficiência oral

\section{Disponível em: http://valueenglish.com/blog/eiken-pre1st-2/}

Apresentado o teste em questão, enfatizamos, conforme já explicitado, que selecionamos as gravações de duas estudantes a partir da constatação da similaridade entre suas respostas ao primeiro questionário sobre rotinas de estudo de língua portuguesa. Esse fato nos chamou a atenção, pois as duas apresentavam um perfil (do próprio ponto de vista) bastante similar, apesar de possuírem níveis de proficiência distintos, pelas observações efetuadas (por nós) em todas as atividades da turma.

Abaixo, apresentamos as perguntas do questionário sobre rotinas de estudo em língua portuguesa e as respostas de cada uma das estudantes, as quais denominamos de estudante A e estudante B. Ambas declaravam-se norte-americanas e, com relação à proficiência oral, de acordo com a nossa observação, a estudante B possuía maior fluência na produção dos enunciados, enquanto a estudante $A$, nos primeiros encontros, destacouse, para nós, pela dificuldade em produzir enunciados completos, uma competência esperada em uma classe de nível avançado. 
Nationality:

United States

Estudante A

\section{Nationality:}

\section{American}

Estudante B

Figura 2. Nacionalidade

Da mesma forma, quando questionadas sobre seu contato com falantes de língua portuguesa, amigos ou parentes, ambas responderam que não possuíam conhecidos com quem conversassem em português. Tal questão, no nosso entender, justificava-se por essa ser uma situação que poderia potencializar as atividades realizadas no âmbito da universidade e influenciar na melhoria da proficiência comunicativa oral, caso tal fato fosse registrado ao final.

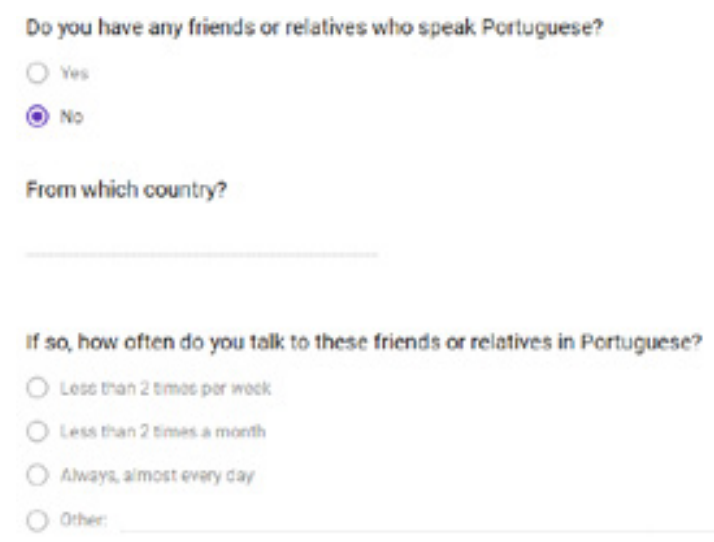

Estudante A

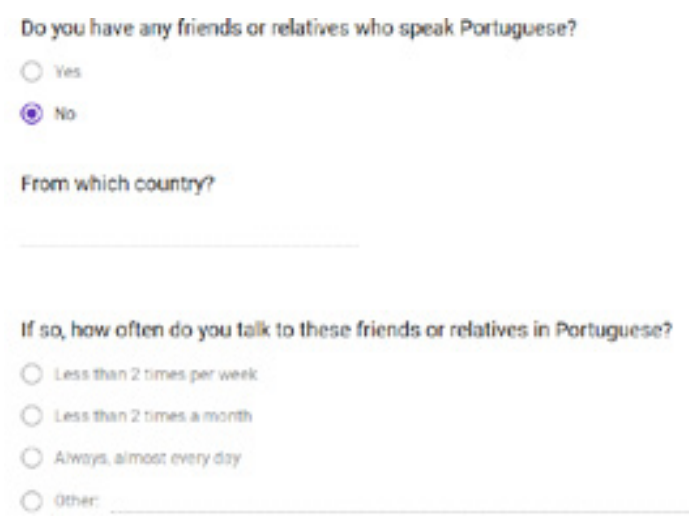

Estudante B

Figura 3. Relação com a língua portuguesa

Quando questionadas sobre sua dedicação aos estudos de língua portuguesa, ambas responderam de forma semelhante, com a diferença de que a estudante $A$, como atividade extra, marcou que escutava músicas e a estudante $B$ marcou que assistia a filmes. As duas, contudo, apenas cumpriam os exercícios da aula e as tarefas obrigatórias, como pode ser observado: 
- | Desenvolvimento da competência comunicativa oral em PLE: teletandem em foco

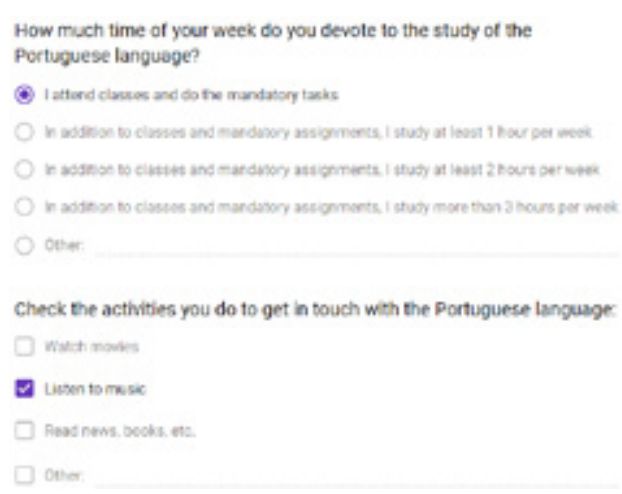

Estudante A

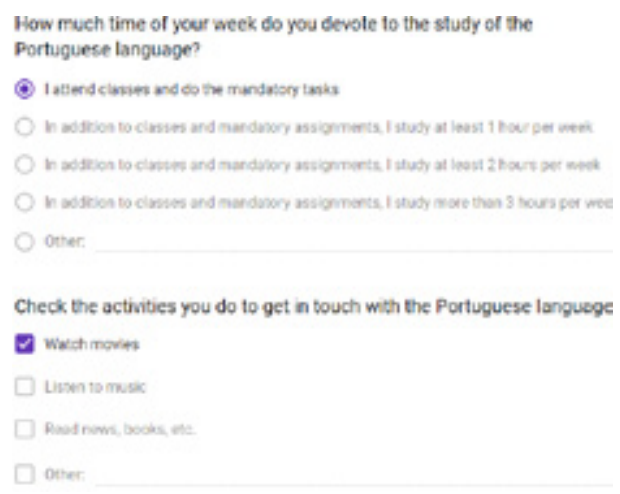

Estudante B

Figura 4. Rotina de estudo de Língua Portuguesa

Quando indagadas acerca de seu nível de proficiência, as duas responderam que se consideravam boas falantes de língua portuguesa, entre as possibilidades (bom, ótimo, excelente). A escolha desses três adjetivos para formular a questão deveu-se ao fato de a turma acompanhada ser uma classe de Língua Portuguesa - Conversação Avançada. Tendo em vista essa classificação, consideramos mais adequado começar a ordenação por (bom) pois, em tese, em uma classe de língua avançada, os alunos possuem um nível de proficiência que supera o nível básico. Já com relação à prática de teletandem, as duas alunas responderam que nunca haviam participado de uma interação antes, conforme pode ser observado abaixo:

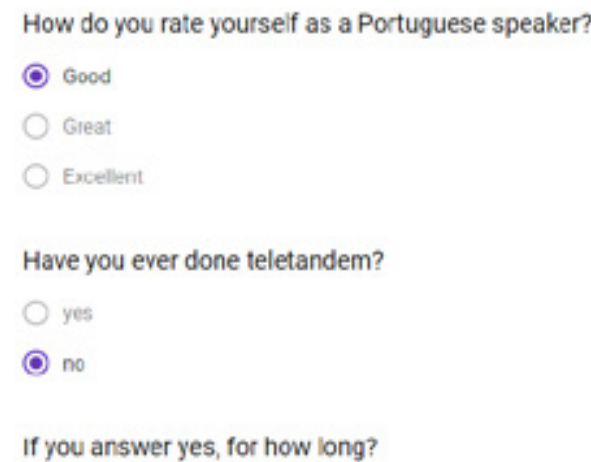

Estudante A

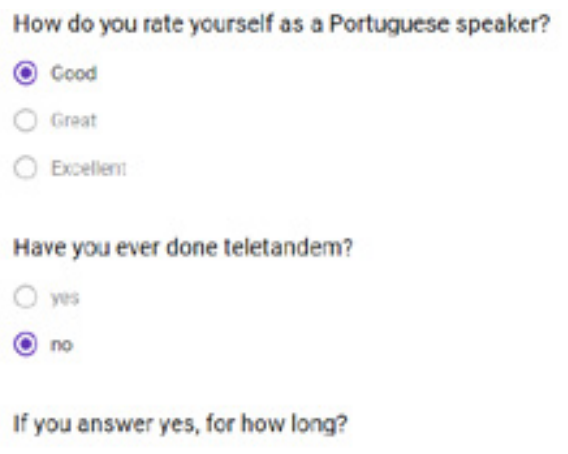

Estudante B

Figura 5. Perfil de falante

Em vista do feedback apresentado pelas duas estudantes ao questionário aplicado, elaboramos um quadro-síntese com as principais características de cada uma, que nos permite observar o perfil de estudante de língua portuguesa: 
Quadro 2. Perfil geral das estudantes em análise

\begin{tabular}{|c|c|}
\hline ESTUDANTE A & ESTUDANTE B \\
\hline Norte-americana & Norte-americana \\
\hline $\begin{array}{c}\text { Não possui amigos ou parentes com quem } \\
\text { converse em língua portuguesa }\end{array}$ & $\begin{array}{c}\text { Não possui amigos ou parentes com quem } \\
\text { converse em língua portuguesa }\end{array}$ \\
\hline $\begin{array}{c}\text { Cumpre as atividades obrigatórias da aula e } \\
\text { faz as tarefas }\end{array}$ & $\begin{array}{c}\text { Cumpre as atividades obrigatórias da aula e } \\
\text { faz as }\end{array}$ \\
\hline $\begin{array}{c}\text { Como ação de aprendizagem adicional, } \\
\text { ouve músicas }\end{array}$ & $\begin{array}{c}\text { Como ação de aprendizagem adicional, } \\
\text { assiste a filmes }\end{array}$ \\
\hline $\begin{array}{c}\text { Considera-se boa falante de português em } \\
\text { um nível entre bom, ótimo e excelente }\end{array}$ & $\begin{array}{c}\text { Considera-se boa falante de português em } \\
\text { um nível entre bom, ótimo e excelente }\end{array}$ \\
\hline Nunca havia feito teletandem & \begin{tabular}{c} 
Nunca havia feito teletandem \\
\hline
\end{tabular}
\end{tabular}

O exposto até o momento ilustra o perfil das estudantes, a partir das respostas a um questionário aplicado, via Google docs, durante o primeiro mês de aulas do grupo, setembro de 2017. Apresentamos, então, o perfil das estudantes, observado pela professora da turma (designada por X) em entrevista concedida a um dos autores (designado por $\mathrm{R}$ ) no final do semestre.

\section{ESTUDANTE A}

X- ela se esforça muito eu acho que ela é a única aluna que não faltou uma aula, (uhum) ela assiste todas as aulas, todas as interações de teletandem. Ela, ela faz quase todas as tarefas eu acho que às vezes ela não entende o que foi a tarefa isso pode ser o problema, eu já tenho pensado nisso, (aham) Ah mas geralmente ela faz tudo ela assiste tudo e ela tem o nível mais baixo na aula (é) de português, mas eu vejo que ela se esforça muito, mesmo nas interações de Teletandem (fala por cima da outra) nossa, ela conversa bastante (aham) em português (sim) mesmo não sabendo as palavras ela sempre pergunta como que se fala isso? Qual a palavra? então, e ela vai estudar no Brasil o semestre que vem, Então eu acho que ela quer realmente aprender sobre a língua a cultura tudo, tem muito interesse apesar de não ter um nível muito avançado. 
- Desenvolvimento da competência comunicativa oral em PLE: teletandem em foco

\section{ESTUDANTE B}

$X$ - Ah! (pausa) Ela participa muito, eu acho que ela participa muito na aula é que pode ser que ela, como o Cristian ela é jovem também porque ela tem faltado algumas aulas e não, não me avisou eu acho que faltou tipo 4, é bastante né, (uhum) mas quando ela sim assisti as aulas ela é uma ótima aluna.

\section{$\mathbf{R}$ - As tarefas ela faz?}

X - Sim, eu acho que sim. Eu não eu não tenho problema com ela quanto às tarefas. Ah! E ela adora as interações (risos) acho que ela gosta muito do parceiro. (Foi uma boa parceria), sim.

Excertos retirados de entrevista com a professora da turma, realizada no dia 5 de dezembro de 2017.

Tendo como parâmetro os apontamentos da professora da turma sobre o envolvimento das duas estudantes com o curso de língua portuguesa, sistematizamos o seguinte quadro:

Quadro 3. Perfil das estudantes observadas, apontado pela professora da turma

\begin{tabular}{|c|c|}
\hline ESTUDANTE A & ESTUDANTE B \\
\hline Se esforça muito, nunca faltou a uma aula & Faltou a algumas aulas e não avisou \\
\hline $\begin{array}{c}\text { Faz todas as tarefas, mas às vezes não } \\
\text { entende as proposições }\end{array}$ & Faz todas as tarefas, não apresenta problema \\
\hline $\begin{array}{c}\text { Está muito envolvida com o teletandem, } \\
\text { se esforça, faz perguntas quando não sabe } \\
\text { como falar }\end{array}$ & $\begin{array}{c}\text { Está envolvida com o teletandem, gosta } \\
\text { muito do parceiro }\end{array}$ \\
\hline $\begin{array}{c}\text { Possui o menor nível de proficiência da sala, } \\
\text { mas é muito esforçada, pois prepara-se para } \\
\text { morar no Brasil no ano seguinte }\end{array}$ & $\begin{array}{c}\text { Possui um bom nível de proficiência e, } \\
\text { apesar de faltar, quando está nas aulas } \\
\text { participa de tudo e é ótima aluna. }\end{array}$ \\
\hline
\end{tabular}




\section{Pré e pós-testes: o que mostram?}

Escolhemos traçar o perfil das estudantes observadas, antes de apresentar sua produção oral (pré e pós-teletandem), em princípio, pela similaridade de suas respostas às questões do Google forms. Embora as duas estudantes possam aparentar ter o mesmo nível de proficiência baseado em suas respostas, a vivência cotidiana nas aulas e nas sessões de teletandem mostraram o contrário. Dessa forma, a caracterização da professora sobre o desempenho das estudantes corrobora as nossas próprias observações sobre os processos de participação nas atividades do curso, durante o segundo semestre de 2017, quando acompanhamos a classe.

A seguir, apresentamos a transcrição do pré e pós-testes das duas estudantes e os observamos a partir do conceito de competência comunicativa de Canalle e Swain (1980), divididas em competências gramatical, discursiva, sociolinguística e estratégica. Inicialmente, pontuaremos questões acerca da competência gramatical, tendo em vista, principalmente, questões de organização textual (caráter sintático de construção de enunciados completos) e competência discursiva, no que tange à sequência da narrativa, tendo em vista que os estudantes "narram" o que visualizam, ou seja, eles contam a história dos quadrinhos.

Essa escolha deveu-se, pois, ao fato de que nossa intenção não é desenvolver análises de cunho fonético aprofundadas, com foco na pronúncia dos alunos. Portanto, acreditamos que a observação dos enunciados transcritos, pelos vieses gramatical (sintático) e discursivo (construção da narrativa) demonstram a fluidez da fala. Tendo por base os estudos de Canale e Swain (1980), Oliveira (2007, p. 69) define competência gramatical:

[...] é o conhecimento que um falante ouvinte possui sobre as regras e as características dessa língua (i.e. a sintaxe, a morfologia, a pronúncia, o vocabulário e a grafia) somado às suas habilidades na utilização desse conhecimento para entender e expressar corretamente o significado literal de enunciados.

Sobre a competência discursiva, também pautado nos estudos de Canale e Swain (1980), Oliveira (2007, p. 70) expõe: 
- Desenvolvimento da competência comunicativa oral em PLE: teletandem em foco

[...] competência discursiva refere-se às regras do discurso. É o conhecimento que o falante-ouvinte tem de combinar formas gramaticais e sentidos para comunicar diferentes tipos de textos, falados ou escritos, de uma maneira unificada, sendo essa unidade textual realizada de duas formas: (a) através da coesão, ao nível da forma lingüística; e (b) através da coerência, ao nível do sentido.

Para atribuir maior visibilidade aos enunciados produzidos nos testes (pré e pós), organizamos tabelas com aqueles que podem constituir um discurso significativo, tendo em vista o que apresenta a figura utilizada no teste (Figura 1. Texto para teste de proficiência oral) como mote para que os estudantes falassem em língua portuguesa.

Baseando-nos no texto do teste e tendo por base o fluxo de sentido discursivo dos enunciados, efetuamos a divisão dos trechos de transcrição por unidades. Para esse estudo, consideramos que quanto menos segmentado o texto, maior será o fluxo de informações com sentido, relacionado à figura tema do teste.

Quadro 4. Comparação entre pré e pós testes estudante A

\begin{tabular}{|c|c|}
\hline PRÉ-TESTE & PÓS-TESTE \\
\hline $\begin{array}{r}\text { na: primeiro aham: o: pai tem uns livros ahm: } \\
\text { sobre o: educação de comput computadora } \\
\text { ahm: } \\
\text { ela fala com o: pai ahm: sobre ahm: como } \\
\text { ela quiere quere, ou quer, ahm o filho } \\
\text { (pausa) para ter o livro e depois ela ahm: tem } \\
\text { o livro } \\
\text { o menino a: gostou na computadora e ahm: } \\
\text { depois o menino ahm: quiere ou quere que } \\
\text { outrU menino "two" ah: jogar jogaram jogam } \\
\text { ahm: com o menino a: na computadora e } \\
\text { no mês próximo ahm: os pais são ahm: fala } \\
\text { sobre a: como o: os meninos não ahm. Jogar } \\
\text { eu acho que ahm: the o o: história é muito } \\
\text { semelhante de a: a maioria de: pessoas de } \\
\text { minha gene generação } \\
\text { e: agora eles ahm: não gosta da gente: ahm: } \\
\text { ahm: para jogar ahm: na computadora, mas } \\
\text { a gente trabalha ahm: na computadora mais, } \\
\text { sim. }\end{array}$ & $\begin{array}{l}\text { no situação ahm: o a mãe ahm: tem um } \\
\text { livro para ahm: educação computadora } \\
\text { ahm: para o seu ou sua ahm: criança e } \\
\text { a: depois ela introdução ahm: no filho } \\
\text { com a computadora e no livro para } \\
\text { educação ahm: então ela ahm: ela gosto: } \\
\text { na computadora e: ahm: nos nas dias } \\
\text { próximos ele introdução se: ahm: seu amigo } \\
\text { a: computadora e ahm: a mês próximos as } \\
\text { países ahm: não gosto o fato a: que as: uhm: } \\
\text { as meninos ahm: não vão jogar no fora e: } \\
\text { ahm: jogar no computadora } \\
\text { acho que no computadora não má } \\
\text { coisa porque é importante para o } \\
\text { desenvolvimento ahm: no futuro e ahm: } \\
\text { as crianças devem ahm: para introdução } \\
\text { no computadora e ahm: mas é importante } \\
\text { para jogar fora também. Eu foi nasce ahm: } \\
\text { jogando fora e: ahm: com as computadoras } \\
\text { então eu gosto ahm: ambos }\end{array}$ \\
\hline
\end{tabular}


Quadro 5. Comparação entre pré e pós testes estudante B

\begin{tabular}{|c|c|}
\hline PRÉ-TESTE & PÓS TESTE \\
\hline $\begin{array}{l}\text { eu me chamo Jojoh... então... a figura fala } \\
\text { sobre uma família a: dois pais... está falando } \\
\text { sobre seu filho que está jogando fora da } \\
\text { casa e a mãe fala sobre um programa de } \\
\text { “computadoras" como educação com o } \\
\text { pai... essa: semana próxima o filho recebeu } \\
\text { uma “computadora" e: uns dias depoiss } \\
\text { "él” convideu seu amigo pra fazer coisas na } \\
\text { sua "computadora" é: depoiss a: os pais se: } \\
\text { preocupam-se porque oss as crianças não } \\
\text { jogam fora (risos)... é: não sei o que devo } \\
\text { falar mais ahm: eu tenho que repassar as } \\
\text { (não compreendi a última palavra). }\end{array}$ & $\begin{array}{l}\text { meu nome é Jojoh... então... nas imagens... } \\
\text { ahm: no primeiro ahm: uns pais falam } \\
\text { sobre um livro que se chama educação de } \\
\text { computador pelos meninos e: pode ver } \\
\text { que seu menino está jogando fora de casa... } \\
\text { a próxima semana a:: mãe "introduce" o } \\
\text { programa de computador a: seu filho e ele } \\
\text { começa a usar o computador ahm: depois } \\
\text { quando seu amigo ahm: vem na casa deles } \\
\text { ahm o menino convida ele para fazer } \\
\text { coisass ahm: pelo computador e a:: tempo } \\
\text { depois os pais veem que os amigos estão } \\
\text { só jogando "jogas" pelo computador e eles } \\
\text { a: se preocupam porque eles basicamente } \\
\text { nunca jogam fora da casa agora (...) } \\
\text { eu acho que demonstra como ahm na: } \\
\text { atualidade, na atual, ah:: os pais querem } \\
\text { introduzir os filhos ao: computador porque } \\
\text { oferece uhm: benefícios possivelmente, } \\
\text { mas, há um, existe um compromisso entre } \\
\text { "jugar" no computador e também fazer as } \\
\text { coisas fora da casa ahm: e pode ser bem } \\
\text { complicado pros pais. }\end{array}$ \\
\hline
\end{tabular}

A observação da transcrição revelou nitidamente a evolução discursiva da estudante A. No pré-teste, considerando nossa participação no processo de aplicação, pela compreensão do contexto, segmentamos o enunciado produzido em oito blocos de sentido. Em contrapartida, no pós-teste, a unidade da narrativa apresentou menos truncamentos, podendo ser dividida em dois blocos significativos. Do ponto de vista da comunicação oral, esse fato é extremamente importante para que se efetive a compreensão entre os interagentes.

Comprovadamente, a estudante evoluiu de forma significativa. A questão é, então, em que medida o teletandem impactou essa transformação? Retomamos o que expõe a própria estudante sobre sua organização com os estudos de língua portuguesa: cumpre todas as tarefas obrigatórias; não faz atividades extras, além de ouvir músicas em português; e 
- | Desenvolvimento da competência comunicativa oral em PLE: teletandem em foco

não possui amigos ou parentes com quem converse em português. A ausência de atividades, fora do que é obrigatório, pensamos, pode corroborar a ideia de que o teletandem possuiu impacto nesse progresso. Seguindo esse raciocínio, atentamos para o fato de que nas aulas de conversação, mesmo que todas as atividades estivessem direcionadas para que os estudantes pudessem expressar-se oralmente, não havia espaço para que esses produzissem mais do que 15 minutos (individualmente) por semana, uma vez que a aula durava, em média, 1h30 e a sala possuía 14 alunos. Sendo assim, a interação semanal de teletandem com o cômputo de 30 minutos semanais, em uma situação concreta de conversação com um falante proficiente é um diferencial incomensurável. Corroborando essa realidade voltamos, aqui, para a constatação efetuada pelo professor que implantou o teletandem na universidade americana na qual o estudo se realizou:

\begin{abstract}
[...] então é: foi uma coisa que eu aproveitei pra começar a testar, brincar com isso porque a minha intuição era de que era melhor um aluno falar trinta minutos por semana na língua alvo de uma vez do que falar três ou quatro minutos por aula num total de quinze minutos né (Trecho entrevista professor M.)
\end{abstract}

No teste da estudante B, ao contrário de A, é mais difícil mensurar o avanço, tendo em vista seu nível de proficiência mais elevado, conforme constatação da professora da turma e de nossa observação acerca de seu desempenho nas atividades letivas. Nesse caso, tendo em vista que as duas produções orais são inteligíveis e têm uma narrativa bem construída, o ponto central está na qualidade da fala em termos de seleção lexical e organização dos períodos. Há maior fluidez no encadeamento das ideias no segundo teste. Não consideramos somente o fato de a segunda produção ser mais extensa em relação à primeira, pois na segunda produção a professora que aplica o teste pergunta sobre a opinião da estudante, o que ocasiona o prolongamento de seu discurso. No primeiro teste, aplicado por nós, não perguntamos sobre a opinião da estudante. Sendo assim, não há justificativa para considerar a extensão do discurso produzido pela estudante, no segundo teste.

Comparando os dois testes, pelo aspecto lexical, por exemplo, constatamos que, no primeiro teste, a estudante A utiliza expressões de língua espanhola: (computadora), em espanhol = la computadora, em português $=$ o computador. Do ponto de vista sintático, pode ser observada, no segundo teste, a construção de um enunciado com orações coordenadas, um pouco mais complexas: "os pais querem introduzir os filhos ao: computador porque oferece uhm: benefícios possivelmente, mas, há um, existe um 
compromisso entre "jugar" no computador e também fazer as coisas fora da casa ahm: e pode ser bem complicado pros pais". Em termos de avaliação de proficiência oral, é bem mais complexo observar o avanço entre os níveis mais elevados, uma vez que as diferenças são, às vezes, bastante sutis e dificultam o trabalho do avaliador. A estudante B inicia o curso em um nível avançado e, consequentemente, avança no ínterim do mesmo nível. Ao contrário da estudante $A$, que começa o curso em um nível de proficiência oral mais próximo do básico (A2) e avança para um nível mais elevado (intermediário B1).

Em embate com as observações que fizemos das aulas e das interações de teletandem enfatizamos, também, o que expôs a professora da turma sobre a estudante A: a aluna era estudiosa, não demonstrava grandes dificuldades nas aulas, apesar de faltar a algumas; participou de todas as interações de teletandem e estabeleceu uma relação bastante positiva com seu parceiro brasileiro. Todas essas características configuram-se como positivas para o desenvolvimento de sua competência comunicativa, apesar de tal estudante esclarecer que cumpria apenas as atividades obrigatórias do curso e, como atividade complementar, assistia a filmes.

\section{Observações das próprias estudantes sobre o teletandem}

No intuito de circundar o fenômeno do avanço da competência oral dos estudantes, conforme explicitado, aplicamos, também, um questionário ${ }^{6}$ em dezembro de 2017, final do semestre. Nesse instrumento, buscamos informações sobre o desenvolvimento individual das interações de teletandem. Abaixo elencamos as respostas dadas às questões, pelas estudantes A e B:
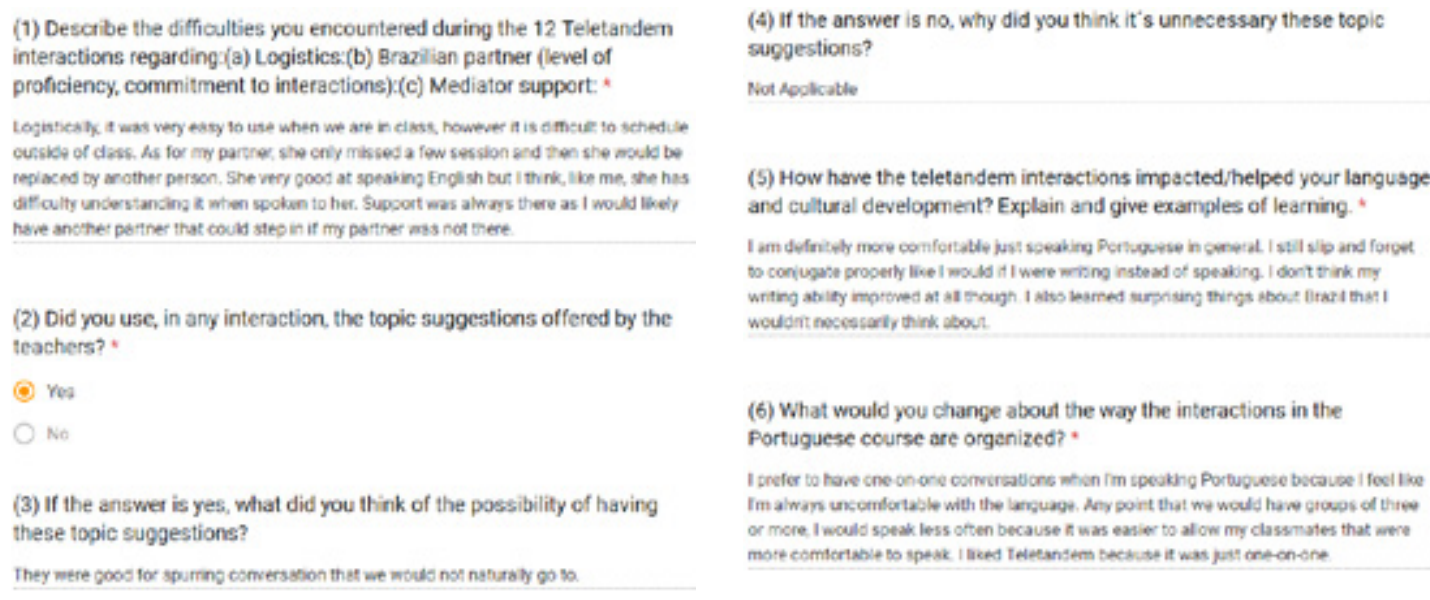

Figura 6. Respostas estudante $A$

6 Rozana Messias, adaptado de QUESTIONNAIRE (TELLES, 2015). 
- | Desenvolvimento da competência comunicativa oral em PLE: teletandem em foco

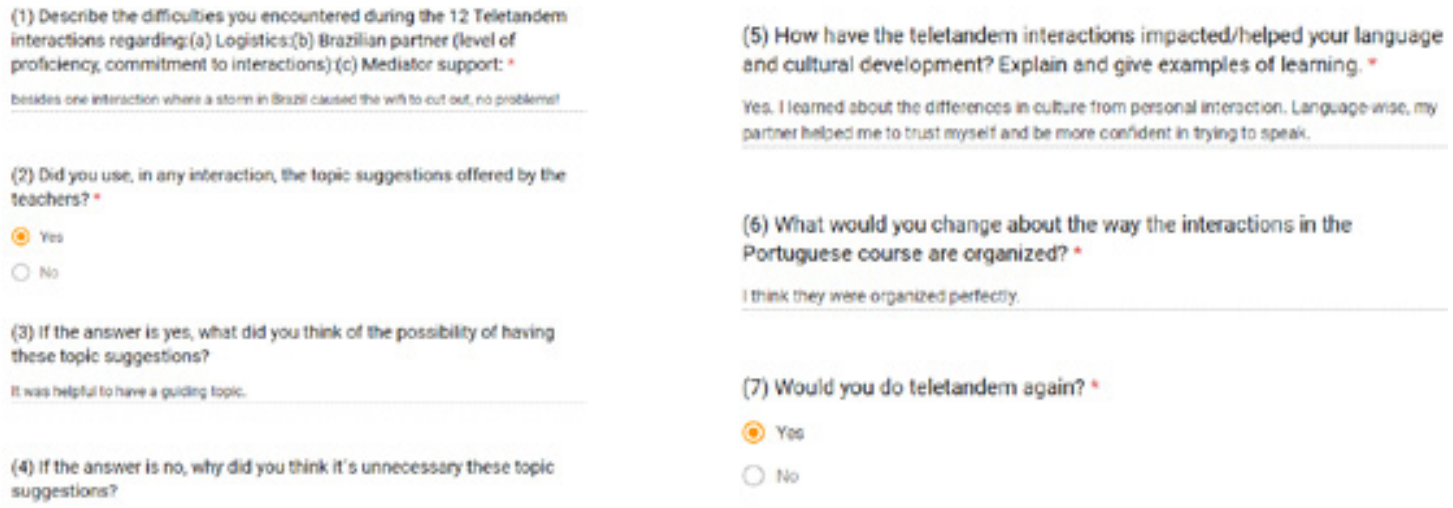

Figura 7. Respostas estudante B

Para o presente estudo, centraremos nossa observação nas questões (1) Describe the difficulties you encountered during the 12 Teletandem interactions regarding: (a) Logistics, (b) Brazilian partner (level of proficiency, commitment to interactions), (c) Mediator support; (5) How have the teletandem interactions impacted/helped your language and cultural development? Explain and give examples of learning e (6) What would you change about the way the interactions in the Portuguese course are organized?

No tocante à questão 1 , sobre as dificuldades encontradas durante as 12 interações, a estudante $A$ expõe que considera a logística fácil, todavia, o mais importante em sua observação é a análise de sua própria proficiência para falar português, em comparação com a parceira que possui mais facilidade com o inglês: "She very good at speaking English but I think, like me, she has difficulty understanding it when spoken to her". A consciência de sua dificuldade, pensamos, levou ao esforço despendido para fazer-se compreender. Suas afirmações, com relação às questões 5 e 6 sobre o impacto das sessões do teletandem no seu desenvolvimento linguístico e a possibilidade de proceder a alguma alteração no modo como as interações foram organizadas, são muito importantes para esclarecer a influência dessa prática no desenvolvimento de sua competência comunicativa oral. Destacamos suas respostas:

I am definitely more comfortable just speaking Portuguese in general. I still slip and forget to conjugate properly like I would if I were writing instead of speaking. I don't think my writing ability improved at all though. I also learned surprising things about Brazil that I wouldn't necessarily think about. (Resposta questão 5) 
I prefer to have one-on-one conversations when I'm speaking Portuguese because I feel like I'm always uncomfortable with the language. Any point that we would have groups of three or more, I would speak less often because it was easier to allow my classmates that were more comfortable to speak. I liked Teletandem because it was just one-on-one. (Resposta questão 6)

A estudante demonstra que se sente mais confortável falando português, depois da experiência de teletandem e reforça também a vantagem de poder falar com uma pessoa (um a um). Em estudo anterior, Telles (2015) já expunha que a maioria dos interagentes de teletandem relatava essa vantagem. Todavia, o diferencial, no caso dessa estudante é a forma como avalia o seu processo e relaciona seu desenvolvimento oral com a prática do teletandem. Isso fica bastante nítido quando demonstra o desconforto com as atividades em grupo, quando preferia deixar que os colegas (que falam melhor) falassem mais do que ela. Nossas observações, durante as aulas, corroboram essa afirmação, pois a aluna falava muito pouco durante as atividades de produção oral nas aulas, em comparação com os demais alunos.

Com relação às respostas da estudante $B$, acreditamos que, por encontrar-se em um estágio mais avançado de proficiência oral, são mais superficiais quanto ao processo, o que, intuímos, pode demonstrar sua segurança nas interações. Ela não observa problemas nas interações e expõe que o teletandem a deixou mais confiante.

Yes. I learned about the differences in culture from personal interaction. Language-wise, my partner helped me to trust myself and be more confident in trying to speak. (Resposta questão 5).

O cerne das respostas da estudante B pode ser diretamente correlacionado aos demais dados a respeito de seu desempenho. As observações da professora, que a avalia como boa aluna, o resultado do pós-teste, que mostra sua evolução em relação ao primeiro e, também, nossas próprias observações das aulas e das interações são momentos em que ela sempre demonstrava segurança e uma produção oral esperada para uma classe de português avançado. 
- | Desenvolvimento da competência comunicativa oral em PLE: teletandem em foco

\section{Considerações finais}

Após rastrear todas as atividades cumpridas pelos estudantes de língua portuguesa de um curso de conversação avançada (com carga horária dividida entre uma aula de conversação e teletandem institucional integrado) de uma universidade norte-americana, durante um semestre letivo, verificamos a concretude do impacto das práticas de teletandem no desenvolvimento da competência comunicativa oral dos praticantes, a partir da observação pormenorizada dos dados produzidos por duas estudantes. Pelas análises, ainda que de apenas duas estudantes, retratamos que a questão central para mensurar o avanço da proficiência oral atrela-se, bastante, ao momento de aprendizagem em que os estudantes se encontram (básico, intermediário ou avançado) e, também, a como o fenômeno é observado pelo pesquisador. O estudo apresentado no presente trabalho carece, ainda, de aprofundamentos no que tange à análise de outros casos, no mesmo grupo.

Da mesma forma, a aplicação do pré e do pós-teste, defendemos, deve ser revista enquanto prática de avaliação focada na análise externa e poderia, pensamos, servir como mais um instrumento de autoavaliação dos estudantes. Acreditamos, também, que essa prática (de mensurar o avanço) pode ser uma ferramenta motivadora para os aprendizes e constitui um mote para se pensar em metodologias de ensino de línguas que, também, auxiliem os professores a visualizar o fenômeno do desenvolvimento da competência oral, com vistas a potencializar o processo de ensino e aprendizagem de línguas.

Os dados analisados até o momento, por sua abrangência em torno de fenômeno do avanço da proficiência oral a partir da prática de teletandem, demonstram que o impacto dessa atividade pode ser mensurado e avaliado pelos professores mediadores. Todavia, é importante, também, que os próprios estudantes se avaliem e se conscientizem de seu desenvolvimento.

\section{Referências}

ANDRÉ, M. E. D. A. Estudo de caso: seu potencial na educação. Cad. de Pesquisa, v. 49, p. 51-54, maio 1984.

ARANHA, S.; CAVALARI, S. M. S. A trajetória do projeto Teletandem Brasil: Da modalidade institucional não-integrada à institucional integrada. The ESPecialist, v. 35, n. 2, p. 183-201, 2014. 
BROCCO, A. S. Avaliação de produções escritas em português para falantes de outras línguas em contexto teletandem: contribuições para a formação inicial de professores. 2014. Tese (Doutorado em Estudos Linguísticos) - Instituto de Biociências, Letras e Ciências Exatas, Universidade Estadual Paulista, São José do Rio Preto, 2014.

CANALE, M.; SWAIN, M. Theoretical bases of communicative approaches to second language teaching and testing. Applied Linguistics. Oxford: Oxford University Press, v. 1, n. 1, p. 1- 47, 1980.

CONSELHO DA EUROPA. Quadro Europeu Comum de Referência para as Línguas Aprendizagem, ensino, avaliação. Tradução Maria Joana Pimentel do Rosário, 2001.

FLICK, U. Uma introdução à pesquisa qualitativa. Tradução Sandra Netz. 2. ed. Porto Alegre: Bookman, 2004.

FURTOSO, V. B.; FERREIRA, M. J. The Impact of Self-Assessment on Learning and Teaching in Technology-Mediated Language Education: User Perceptions of the Teletandem Tracking Sheet. In: Useful assessment and evaluation in language education. John McE. Davis, John M. Norris, Margaret E. Malone, Todd H. McKay, and Young-A Son, Editors. Georgetown, 2018.

FURTOSO, V. A. B. Desempenho oral em português para falantes de outras línguas: da avaliação à aprendizagem de línguas estrangeiras em contexto online. 2011. Tese (Doutorado em Estudos Linguísticos) - Instituto de Biociências, Letras e Ciências Exatas, Universidade Estadual Paulista, São José do Rio Preto, 2011.

MESSIAS, R. A. L.; TELLES, J. A. Teletandem como "terceiro espaço" no desenvolvimento de professores de línguas estrangeiras. (mimeo)

OLIVEIRA, L. A. O conceito de competência no ensino de Línguas estrangeiras. Sitientibus, Feira de Santana, v. 37, p. 61-74, jul./dez. 2007.

TEITELBAUM, K.; APPLE, M. John Dewey. Currículo sem Fronteiras, v. 1, n. 2, p. 194-201, jul./dez. 2001.

TELLES, J. A. Learning foreign languages in teletandem: Resources and strategies. DELTARevista de Estudos em Linguística Teórica e Aplicada, v. 31, n. 3, p. 603-632, 2015. 
- | Desenvolvimento da competência comunicativa oral em PLE: teletandem em foco

TELLES, J. A. Teletandem: metamorfoses impostas pela tecnologia sobre o ensino de línguas estrangeiras. In: TELLES, J. A. (org.). Teletandem: um contexto virtual, autônomo e colaborativo para aprendizagem de línguas estrangeiras no século XXI. Campinas: Pontes Editores, 2009. p. 63-73.

TELLES, J. A. Learning foreign languages in teletandem: Resources and strategies. DELTA Revista de Estudos em Linguística Teórica e Aplicada, v. 31, n. 3, p. 651-680, 2015.

TELLES, J. A. Teletandem: Transculturalidade nas interações online em línguas estrangeiras via webcam. Projeto de Pesquisa, 2011. Disponível em: http://www.teletandembrasil.org/ site/docs/TELLESTRANSCULTPROJECT2011.pdf.24. Acesso em: 08 dez. 2018.

TELLES, J. A.; VASSALLO, M. L. Teletandem: uma proposta alternativa no ensino aprendizagem assistidos por computadores. In: TELLES, J. A. (org.). Teletandem: um contexto virtual, autônomo e colaborativo para aprendizagem de línguas estrangeiras no século XXI. Campinas: Pontes Editores, 2009. p. 41-61.

COMO CITAR ESTE ARTIGO: LOPES MESSIAS, Rozana Aparecida; FERREIRA, Michael J. Desenvolvimento da competência comunicativa oral em PLE: teletandem em foco. Revista do GEL, v. 15, n. 3, p. 131-154, 2018. Disponível em: https://revistadogel.gel.org.br/

DOI: http://dx.doi.org/10.21165/gel.v15i3.2412

Submetido em: 17/11/2018 | Aceito em: 28/12/2018. 